\title{
Antihyperlipidemic Effect of a Polyherbal Mixture in Streptozotocin-Induced Diabetic Rats
}

\author{
Ahmad Ghorbani, ${ }^{1}$ Reza Shafiee-Nick, ${ }^{1,2}$ Hassan Rakhshandeh, ${ }^{1,2}$ and Abasalt Borji ${ }^{3}$ \\ ${ }^{1}$ Pharmacological Research Center of Medicinal Plants, School of Medicine, Mashhad University of Medical Sciences, \\ Mashhad 9177948564, Iran \\ ${ }^{2}$ Department of Pharmacology, School of Medicine, Mashhad University of Medical Sciences, Mashhad 9177948564, Iran \\ ${ }^{3}$ Neyshabur University of Medical Sciences, Neyshabur 93186-14139, Iran
}

Correspondence should be addressed to Reza Shafiee-Nick; shafieer@mums.ac.ir

Received 8 June 2013; Revised 17 October 2013; Accepted 21 October 2013

Academic Editor: Angel Catalá

Copyright (C) 2013 Ahmad Ghorbani et al. This is an open access article distributed under the Creative Commons Attribution License, which permits unrestricted use, distribution, and reproduction in any medium, provided the original work is properly cited.

The effects of a polyherbal mixture containing Allium sativum, Cinnamomum zeylanicum, Citrullus colocynthis, Juglans regia, Nigella sativa, Olea europaea, Punica granatum, Salvia officinalis, Teucrium polium, Trigonella foenum, Urtica dioica, and Vaccinium arctostaphylos were tested on biochemical parameters in diabetic rats. The animals were randomized into three groups: (1) normal control, (2) diabetic control, and (3) diabetic rats which received diet containing $15 \%(\mathrm{w} / \mathrm{w})$ of this mixture for 4 weeks. Diabetes was induced by intraperitoneal injection of streptozotocin $(55 \mathrm{mg} / \mathrm{kg})$. At the end of experiment, the mixture had no significant effect on serum hepatic enzymes, aspartate aminotransferase, and alanine aminotransferase activities. However, the level of fasting blood glucose, water intake, and urine output in treated group was lower than that in diabetic control rats $(P<0.01)$. Also, the levels of triglyceride and total cholesterol in polyherbal mixture treated rats were significantly lower than those in diabetic control group $(P<0.05)$. Our results demonstrated that this polyherbal mixture has beneficial effects on blood glucose and lipid profile and it has the potential to be used as a dietary supplement for the management of diabetes.

\section{Introduction}

Diabetes mellitus, a metabolic disease with manifestation of hyperglycemia and dyslipidemia, is still one of the most leading causes of death and disability. Over time, diabetes leads to serious complications such as nephropathy, retinopathy, neuropathy, stroke, and peripheral vascular diseases [1]. Currently, beside insulin, the most widely used medications for diabetes are insulin and the oral hypoglycemic drugs [2]. Although early onset manifestations of diabetes can be controlled by current antidiabetic drugs, late onset complications appear in many patients [3]. In addition, the clinical uses of the current drugs are usually accompanied with some adverse effects including abdominal discomfort, severe hypoglycemia, lactic acidosis, and peripheral edema [2]. Therefore, the search for new antidiabetic agents with more effectiveness and lesser side effects has continued.
Today, antidiabetic effects of several plants have been supported by results from animal studies or clinical trials. Among them, Allium sativum, Cinnamomum zeylanicum, Citrullus colocynthis, Juglans regia, Nigella sativa, Olea europaea, Punica granatum, Salvia officinalis, Teucrium polium, Trigonella foenum, Urtica dioica, and Vaccinium arctostaphylos are widely used as medicinal plants for management of diabetes $[4,5]$. Several studies have shown that each one of these plants is effective in the decrease of plasma glucose and serum lipids in diabetes [6-18]. We hypothesized that a combination of them may have more beneficial effect on improving metabolic indexes. The present study is a part of a research effort to develop the best polyherbal mixture from these antidiabetic plants for management of glucose and lipid in diabetes. In our previous work, we observed that administration of a combination of hydroalcoholic extracts of six of them inhibited the progression of hyperglycemia and 
decreased serum lipids and hepatic enzyme activity in diabetic rats [19]. Since nonprocessed herbs are usually more tolerated than extracted or formulated products and patients prefer to consume plants as salad, spice, and so forth, in this work, we aimed to investigate the effect of a mixture of powders of the above mentioned twelve plants on glycemic and lipidemic status of diabetic rats.

\section{Materials and Methods}

2.1. Preparation of Polyherbal Mixture. The air-dried A. sativum (cloves), C. zeylanicum (bark), C. colocynthis (fruit), J. regia (leaf), N. sativa (seeds), O. europaea (leaf), P. granatum (fruit), S. officinalis (areal parts), T. polium (areal parts), T. foenum (seeds), U. dioica (areal parts), and V. arctostaphylos (fruit) were powdered and mixed with ratio of $5 \%, 5 \%, 5 \%$, $10 \%, 5 \%, 5 \%, 5 \%, 5 \%, 5 \%, 20 \%, 15 \%$, and $15 \%$, respectively. This polyherbal mixture (PHM) was added (15\% w/w) to the standard pellets diet of animals in treatment group.

2.2. Animals. Male albino Wistar rats (280-330 g) were obtained from Laboratory Animals House, Mashhad Medical University (Iran) and housed in a room with controlled lighting (12 h light/12 h darkness) and temperature $\left(22 \pm 2^{\circ} \mathrm{C}\right)$. The animals were given standard pellets diet and water ad libitum. All animal procedures were done according to the ethical guidelines of the animal care of Shiraz University of Medical Sciences (Iran). To generate diabetes, some rats received a single dose $(55 \mathrm{mg} / \mathrm{kg}$, ip) of streptozotocin (STZ) (Enzo Life, USA). Induction of diabetes was confirmed by measuring fasting blood glucose (FBG) two days after STZ injection. Rats with FBG level of $250 \mathrm{mg} / \mathrm{kg}$ or higher were considered to be diabetic $[20,21]$.

2.3. Groups of Study. The animals were randomized into three groups: (1) normal control rats which were fed standard diet $(n=6)$, (2) diabetic control animals which were fed standard diet $(n=6)$, and (3) diabetic rats which received diet containing $15 \%(\mathrm{w} / \mathrm{w})$ of PHM $(n=8)$. The treatment was initiated two days after STZ injection and continued for 4 weeks. At the end of the 30th day, the rats fasted $16 \mathrm{~h}$ and blood samples were collected from retroorbital sinus for biochemical measurements. At the end of the experiment, animals were placed in individual metabolic cages for urinary collection. After acclimatization (1 day), the $24 \mathrm{~h}$ urinary samples were collected from diabetic animals.

2.4. Biochemical Assays. Serum triglyceride and total cholesterol were evaluated with standard enzymatic colorimetric kits from Pars Azmun (Iran). Blood glucose was measured using glucose oxidase reagent (Ziest Chem Diagnostics, Iran). Serum aspartate aminotransferase (AST) and alanine aminotransferase (ALT) activities were evaluated with colorimetric methods by commercially available kits (Pars Azmun, Iran).

2.5. Statistical Analysis. Analysis of changes from baseline was performed by paired $t$-test within groups. Intergroup comparison was done by one-way ANOVA with Tukey's

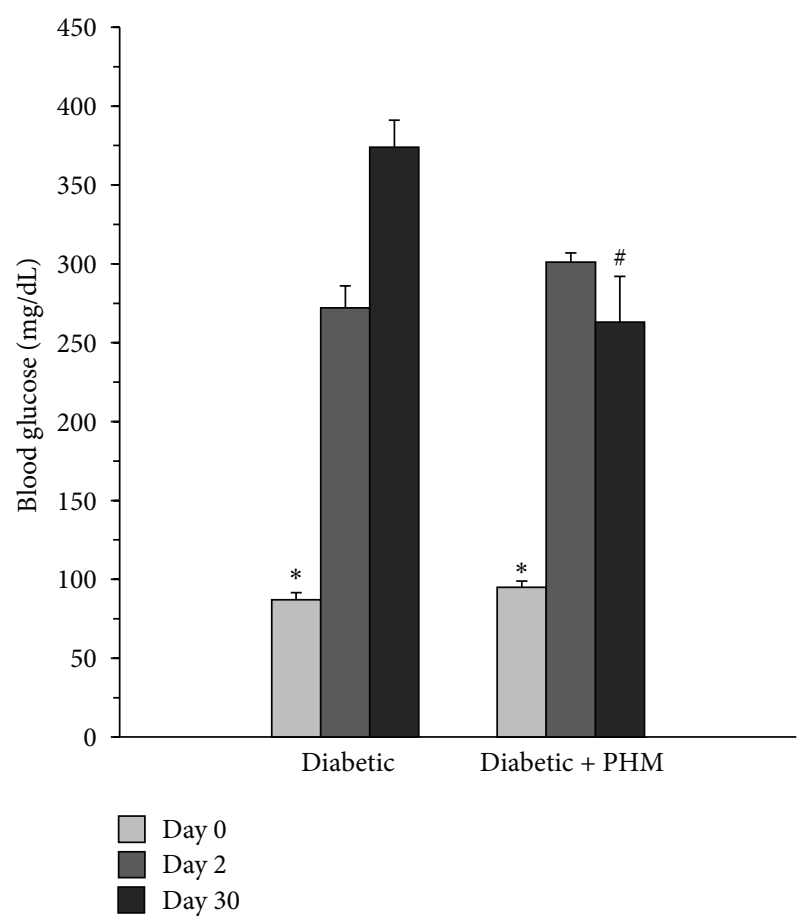

FIGURE 1: Effects of the polyherbal mixture (PHM) on blood glucose. The animals in group of diabetic + PHM received PHM for 4 weeks. ${ }^{*} P<0.01$ compared with day 2 and day 30 at the corresponding group. ${ }^{\#} P<0.01$ compared with the corresponding value in diabetic control group. The data are expressed as mean \pm SEM for eight (diabetic + PHM) or six (normal and diabetic control) rats.

posthoc test. Results showing $P$ values less than 0.05 were considered significant.

\section{Results}

3.1. Effect of PHM on Blood Glucose. As shown in Figure 1, before injection of STZ, FBG levels of both groups were statistically not different from each other. At day 2, administration of STZ led to an approximately 3-fold increase in FBG level. The diabetic rats in control group showed further increase of FBG at the end of experiment $(374 \pm 17 \mathrm{mg} / \mathrm{dL}$ in day 30 versus $272 \pm 14 \mathrm{mg} / \mathrm{dL}$ in day $2, P<0.01)$. However, administration of PHM to diabetic rats blocked the increase of blood glucose. At day 30, the level of FBG in this group was $263 \pm 29 \mathrm{mg} / \mathrm{dL}$ which was significantly lower than that in diabetic control rats $(P<0.01)$.

3.2. Effect of PHM on Body Weight, Water Intake, and Urine Output. During experiment, both diabetic control and diabetic PHM treated groups exhibited a significant reduction in their body weight. At day 30, the weight reduction reached to $27 \%(P<0.001$ versus day 0$)$ and $25 \%(P<0.001$ versus day 0) for control and PHM treated animals, respectively (Table 1). Prior to diabetes induction, the level of water intake was not significantly different between three groups. However, after STZ administration, there was a significant increase in the levels of water intake in both groups of diabetic rats. Although the polydipsia condition was evident during 
TABLE 1: Effects of the polyherbal mixture (PHM) on body weight and water intake. The animals in group of diabetic + PHM received PHM for 4 weeks.

\begin{tabular}{lcccccc}
\hline \multirow{2}{*}{ Animal groups } & \multicolumn{2}{c}{ Body weight $($ gram) } & \multicolumn{2}{c}{ Water intake $(\mathrm{mL} / 24 \mathrm{~h})$} & \multicolumn{2}{c}{ Urine $(\mathrm{mL} / 24 \mathrm{~h})$} \\
& Day 0 & Day 30 & Day 0 & Day 16 & Day 30 & Day 30 \\
\hline Normal control & $311 \pm 5$ & $360 \pm 7^{*}$ & $37 \pm 3$ & $50 \pm 4^{\infty}$ & $42 \pm 2^{\infty}$ & - \\
Diabetic control & $314 \pm 6$ & $230 \pm 6^{* *}$ & $42 \pm 2$ & $137 \pm 7^{\#}$ & $143 \pm 11^{\#}$ & $72 \pm 9$ \\
Diabetic + PHM & $300 \pm 6$ & $223 \pm 6^{* *}$ & $40 \pm 3$ & $84 \pm 2^{\# \times}$ & $100 \pm 9^{\# \times}$ & $30 \pm 3^{\times}$ \\
\hline
\end{tabular}

${ }^{*} P<0.05$ compared with day 0 in the corresponding group. ${ }^{* *} P<0.001$ compared with day 0 in the corresponding group. ${ }^{\#} P<0.001$ compared with the corresponding values at day $0 .{ }^{\infty} P<0.001$ compared with the corresponding values of diabetic and diabetic + PHM groups. ${ }^{\times} P<0.01$ compared with the corresponding values of diabetic group. The data are expressed as mean \pm SEM for eight (diabetic + PHM) or six (normal and diabetic control) rats.

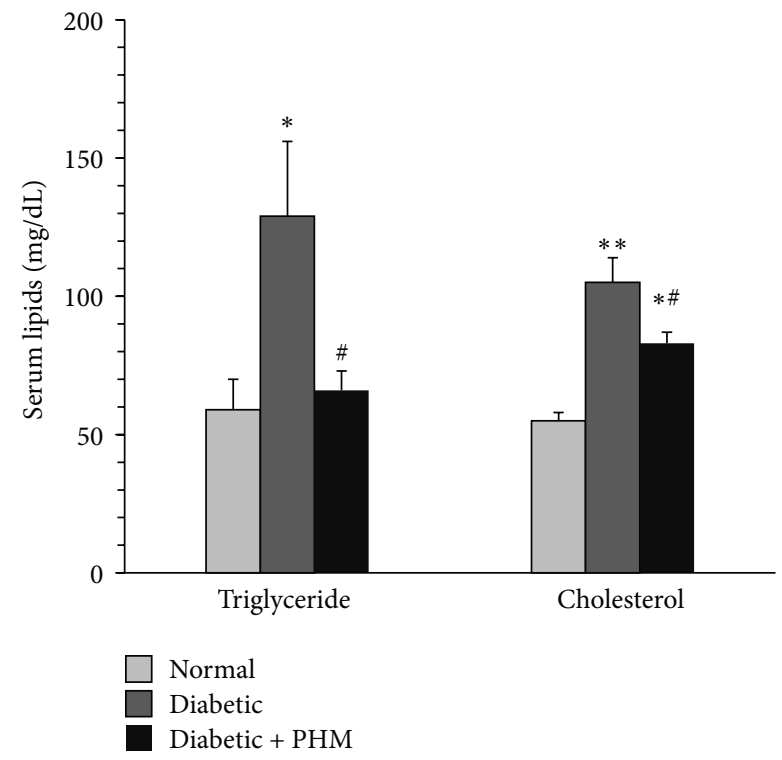

FIGURE 2: Effects of the polyherbal mixture (PHM) on the levels of plasma lipids. The animals in group of diabetic + PHM received PHM for 4 weeks. ${ }^{*} P<0.05$ versus normal rats. ${ }^{* *} P<0.01$ versus normal rats. ${ }^{*} P<0.05$ versus diabetic control. The data are expressed as mean \pm SEM for eight (diabetic + PHM) or six (normal and diabetic control) rats.

the treatment period, the level of water intake in PHM group was significantly $(P<0.001)$ lower than that in diabetic control group. Also, at the end of the experiment, the PHMfed diabetic rats showed an improvement in polyurea state and the excretion of urine was significantly lower than that of diabetic control group $(30 \pm 3 \mathrm{~mL} / 24 \mathrm{~h}$ versus $72 \pm 9 \mathrm{~mL} / 24 \mathrm{~h}$, $P<0.01)$.

3.3. Effect of PHM on Serum Lipids. Figure 2 shows the level of serum lipids in study groups. There was a significant elevation in the level of triglyceride $(129 \pm 27 \mathrm{mg} / \mathrm{dL}$ versus $59 \pm 11 \mathrm{mg} / \mathrm{dL}, P<0.05)$ and total cholesterol $(105 \pm 9 \mathrm{mg} /$ $\mathrm{dL}$ versus $55 \pm 3 \mathrm{mg} / \mathrm{dL}, P<0.01)$ in diabetic control rats as compared with normal group. The PHM was found to be effective in decreasing serum lipids. The levels of triglyceride and total cholesterol in PHM treated group were $66 \pm$ $27 \mathrm{mg} / \mathrm{dL}(P<0.05$ versus diabetic control group $)$ and $83 \pm 4 \mathrm{mg} / \mathrm{dL}(P<0.05$ versus diabetic control group $)$, respectively.

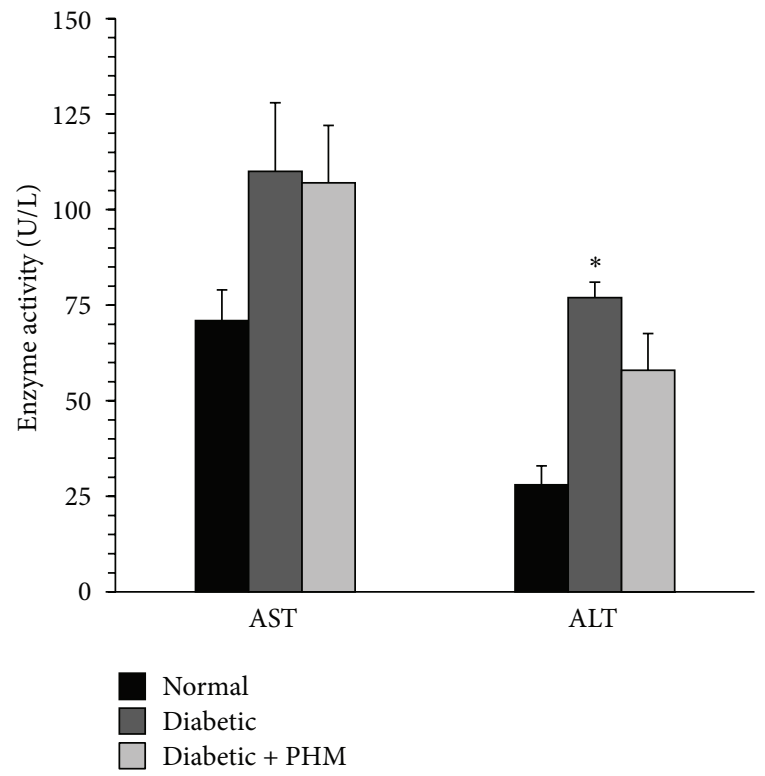

FIGURE 3: Effects of the polyherbal mixture (PHM) on serum aspartate aminotransferase (AST) and alanine aminotransferase (ALT) activities. The animals in group of diabetic + PHM received PHM for 4 weeks. ${ }^{*} P<0.05$ versus normal control rats. The data are expressed as mean \pm SEM for eight (diabetic + PHM) or six (normal and diabetic control) rats.

3.4. Effect of PHM on Hepatic Enzymes. At day 30, diabetic control rats showed higher AST $(110 \pm 18$ versus $71 \pm 8 \mathrm{U} / \mathrm{L})$ and ALT $(77 \pm 4$ versus $28 \pm 5 \mathrm{U} / \mathrm{L}, P<0.05)$ activity than that of normal group, suggesting hepatic dysfunction in these animals. The level of AST and ALT activity in PHM treated groups was $107 \pm 15 \mathrm{U} / \mathrm{L}$ and $58 \pm 10 \mathrm{U} / \mathrm{L}$, respectively, which was not significantly different from that of diabetic control rats (Figure 3).

\section{Discussion}

Although numerous herbs have been suggested for the treatment of diabetes, but at present no one could completely treat diabetic patients. One approach for the development of an effective phytochemical compound can be mixing a number of hypoglycemic and hypolipidemic herbs to produce more potent antidiabetic agent. The present work was a part of a research effort to find the best mixture from 
some medicinal plants which their hypoglycemic and hypolipidemic effects were supported by several studies. Here, we investigated the effect of a diet containing mixture of twelve medicinal plants on glycemic and lipidemic status of diabetic rats. Although this mixture failed to completely restore STZ-induced hyperglycemia and had no effect on weight reduction, it significantly prevented further elevation of blood sugar and improved the polydipsia and polyurea. This beneficial effect on glycemic status is expected to happen as antihyperglycemic effect of all twelve plants forming PHM has been confirmed with repeated studies [6-16, 22, 23]. Antihyperglycemic effect of medicinal plants is achieved by different mechanisms including decreasing glucose absorption from intestine, enhancing insulin secretion from beta cells, increasing glucose uptake by tissues, inhibiting glucose production in liver, and increasing pancreatic tissue regeneration and/or presence of insulin-like agents in plants [24-27]. Regarding PHM, inhibitory effect of T. foenum on intestinal glucose absorption and the beneficial effects of $J$. regia and T. polium on regeneration of pancreatic islets were reported [28-30]. Also, it has been demonstrated that N. sativa and $S$. officinalis decrease hepatic glucose production through inhibition of gluconeogenic enzymes [31, 32]. Furthermore, the insulin secretory effects of C. colocynthis, O. europaea, $T$. foenum, $V$. arctostaphylos, and $U$. dioica were shown in vitro in the isolated pancreas or islets [16, 17, 33-35].

Diabetes is often associated with dyslipidemia, a main risk factor of cardiovascular diseases. Therefore, the levels of serum triglyceride and cholesterol are usually elevated in diabetic patients [36]. In our study, PHM could decrease serum triglyceride level and attenuate hypercholesterolemia. The hypolipidemic action of PHM is in agreement with earlier studies that reported that A. sativum, C. colocynthis, C. zeylanicum, J. regia, N. sativa, S. officinalis, P. granatum, T. foenum, and $T$. polium decrease the levels of serum triglyceride and cholesterol in diabetic subjects $[6,7,9,12,14$, 37-39]. Also, in our previous work, we showed that T. foenum led to a significant reduction in lipid droplet accumulation in adipocytes [40].

Elevation of ALT and AST enzyme activities is considered as an evidence for hepatic damage. An increase of these enzyme activities is also associated with fatty liver disease and decreased hepatic insulin sensitivity in type 2 diabetes [41, 42]. According to the reports of previous studies, $A$. sativum, J. regia, S. officinalis, O. europaea, T. foenum, and T. polium could decrease the ALT and AST levels in diabetic rats $[7,8,37,43-45]$. On the other hand, there are some reports that chronic administration of T. polium results in elevation in plasma levels of liver enzymes [15, 46]. In our study, the PHM has no significant effect on ALT and AST activity. Therefore, consumption of this polyherbal mixture accompanied with no hepatoprotective or hepatotoxic activity.

Taken together, our results demonstrated that PHM has beneficial effects on blood glucose and lipid profile of diabetic rats. In our previous work, we observed approximately the same level of antihyperglycemic and hypolipidemic effect with administration of a polyherbal mixture made from the combination of macerated and Soxhlet (hydroalcoholic) extracts of A. sativum, C. zeylanicum, N. sativa, P. granatum,
S. officinalis, and T. polium [19]. Therefore, we did not find any favorable effects on diabetes when the powders of twelve plants were combined instead of giving a combination of hydroalcoholic extracts of six of these plants. Also, some studies reported more antihyperglycemic effect when the extracted or formulated products of herbs especially $T$. foenum were given individually [28]. However, it should be considered that when they are administrated individually, the antidiabetic effect was achieved usually with high doses of the plant extract which may be accompanied with unpleasant effects in the body [47]. Therefore, we still believed that the PHM, which was constructed simply from mixing plant powders without the need for extraction procedure, has the potential to be used as a dietary supplement for the management of diabetes, particularly diabetic dyslipidemia. Obviously, more study is needed to find a more potent polyherbal mixture from antidiabetic plants. Further, combination of active ingredients isolated from these plants may be a subject if interest in future perspective related to diabetes management.

\section{Acknowledgments}

This work was supported by a grant from Research Council of Mashhad University of Medical Sciences and Neyshabur University of Medical Sciences. The authors declare that they have no conflict of interests.

\section{References}

[1] A. D. Deshpande, M. Harris-Hayes, and M. Schootman, "Epidemiology of diabetes and diabetes-related complications," Physical Therapy, vol. 88, no. 11, pp. 1254-1264, 2008.

[2] B. Lorenzati, C. Zucco, S. Miglietta, F. Lamberti, and G. Bruno, "Oral hypoglycemic drugs: pathophysiological basis of their mechanism of action," Pharmaceuticals, vol. 3, no. 9, pp. 30053020,2010 .

[3] I. Tzoulaki, M. Molokhia, V. Curcin et al., "Risk of cardiovascular disease and all cause mortality among patients with type 2 diabetes prescribed oral antidiabetes drugs: retrospective cohort study using UK general practice research database," British Medical Journal, vol. 339, p. b4731, 2009.

[4] A. Ghorbani, "Best herbs for managing diabetes: a review of clinical studies," Brazilian Journal of Pharmaceutical Sciences, vol. 49, no. 3, pp. 413-422, 2013.

[5] A. Ghorbani, "Phytotherapy for diabetic dyslipidemia: evidence from clinical trials," Clinical Lipidology, vol. 8, pp. 311-319, 2013.

[6] K. Divband, G. R. Komeyli, and F. Saeidinik, "Effects of walnut leaves aqueous extract on blood sugar and serum lipids in diabetic rats," Journal of Birjand University of Medical Sciences, vol. 17, pp. 11-18, 2010.

[7] A. Eidi, M. Eidi, and E. Esmaeili, "Antidiabetic effect of garlic (Allium sativum L.) in normal and streptozotocin-induced diabetic rats," Phytomedicine, vol. 13, no. 9-10, pp. 624-629, 2006.

[8] A. Eidi, M. Eidi, and R. Darzi, "Antidiabetic effect of Olea europaea l. in normal and diabetic rats," Phytotherapy Research, vol. 23, no. 3, pp. 347-350, 2009.

[9] A. Esmaillzadeh, F. Tahbaz, I. Gaieni, H. Alavi-Majd, and L. Azadbakht, "Cholesterol-lowering effect of concentrated 
pomegranate juice consumption in type II diabetic patients with hyperlipidemia," International Journal for Vitamin and Nutrition Research, vol. 76, no. 3, pp. 147-151, 2006.

[10] H. F. Huseini, F. Darvishzadeh, R. Heshmat, Z. Jafariazar, M. Raza, and B. Larijani, "The clinical investigation of Citrullus colocynthis (L.) schrad fruit in treatment of type II diabetic patients: a randomized, double blind, placebo-controlled clinical trial," Phytotherapy Research, vol. 23, no. 8, pp. 1186-1189, 2009.

[11] M. J. Golalipour and V. Khori, “The protective activity of Urtica dioica leaves on blood glucose concentration and $\beta$-cells in streptozotocin-diabetic rats," Pakistan Journal of Biological Sciences, vol. 10, no. 8, pp. 1200-1204, 2007.

[12] S. A. Hassan, R. Barthwal, M. S. Nair, and S. S. Haque, "Aqueous bark extract of Cinnamomum Zeylanicum: a potential therapeutic agent for streptozotocin-induced type 1 diabetes mellitus (T1DM) rats," Tropical Journal of Pharmaceutical Research, vol. 13, pp. 429-435, 2012.

[13] H. Jemai, A. E. L. Feki, and S. Sayadi, "Antidiabetic and antioxidant effects of hydroxytyrosol and oleuropein from olive leaves in alloxan-diabetic rats," Journal of Agricultural and Food Chemistry, vol. 57, no. 19, pp. 8798-8804, 2009.

[14] M. Kaleem, D. Kirmani, M. Asif, Q. Ahmed, and B. Bano, "Biochemical effects of Nigella sativa L seeds in diabetic rats," Indian Journal of Experimental Biology, vol. 44, no. 9, pp. 745748, 2006.

[15] M. R. Shahraki, M. R. Arab, E. Mirimokaddam, and M. J. Palan, "The effect of Teucrium polium (Calpoureh) on liver function, serum lipids and glucose in diabetic male rats," Iranian Biomedical Journal, vol. 11, no. 1, pp. 65-68, 2007.

[16] D. Puri, K. M. Prabhu, and P. S. Murthy, "Mechanism of action of a hypoglycemic principle isolated from fenugreek seeds," Indian Journal of Physiology and Pharmacology, vol. 46, no. 4, pp. 457-462, 2002.

[17] R. Shafiee-Nick, S. M. R. Parizadeh, N. Zokaei, and A. Ghorbani, "Effect of hydro-alcoholic extract of Vaccinium arctostaphylos on insulin release from rat-isolated langerhans islets," Koomesh, vol. 12, pp. 447-452, 2011.

[18] R. Premanath, N. Lakshmidevi, K. Jayashree, and R. N. Suresh, "Evaluation of anti-diabetic effect of Trigonella foenum graecum Linn. Leaf extract in streptozotocin induced diabetic rats," International Journal of Diabetes in Developing Countries, vol. 32, pp. 138-144, 2012.

[19] R. Shafiee-Nick, A. Ghorbani, F. Vafaee, and H. Rakhshandeh, "Chronic administration of a combination of six herbs inhibits the progression of hyperglycemia and decreases serum lipids and aspartate amino transferase activity in diabetic rats," Advances in Pharmacological Sciences, vol. 2012, Article ID 789796, 6 pages, 2012.

[20] A. Ghorbani, M. Varedi, M.-A.-R. Hadjzadeh, and G. H. Omrani, "Type-1 diabetes induces depot-specific alterations in adipocyte diameter and mass of adipose tissues in the rat," Experimental and Clinical Endocrinology and Diabetes, vol. 118, no. 7, pp. 442-448, 2010.

[21] A. Ghorbani, G. H. Omrani, M. R. Hadjzadeh, and M. Varedi, "Proinsulin C-peptide inhibits lipolysis in diabetic rat adipose tissue through phosphodiestrase-3B enzyme," Hormone and Metabolic Research, vol. 45, no. 3, pp. 221-225, 2013.

[22] K. S. Shaughnessy, L. J. Gabor, K. T. Gottschall-Pass, and M. I. Sweeny, "Blueberry diets improve glucose tolerance and decrease oxidative stress in spontaneously hypertensive strokeprone rats," The FASEB Journal, vol. 22, pp. 702-705, 2008.
[23] S. Radhika, K. H. Smila, and R. Muthezhilan, "Antidiabetic and hypolipidemic activity of Punica granatum linn on alloxan induced rats," World Journal of Medical Sciences, vol. 6, no. 4, pp. 178-182, 2011.

[24] A. M. Gray and P. R. Flatt, "Insulin-releasing and insulinlike activity of the traditional anti-diabetic plant Coriandrum sativum (coriander)," British Journal of Nutrition, vol. 81, no. 3, pp. 203-209, 1999.

[25] H. Hui, G. Tang, and V. L. W. Go, "Hypoglycemic herbs and their action mechanisms," Chinese Medicine, vol. 4, article 11, 2009.

[26] K. R. Shanmugasundaram, C. Panneerselvam, P. Samudram, and E. R. B. Shanmugasundaram, "The insulinotropic activity of Gymnema sylvestre, R.Br. an Indian medical herb used in controlling diabetes mellitus," Pharmacological Research Communications, vol. 13, no. 5, pp. 475-486, 1981.

[27] H.-L. Xue, Z. Zhang, W.-J. Wang, W.-H. Chen, and J. Ying, "Effects of Chinese herbal medicine Yiqi Zengmin formula on expression of glucose transporter 4 in skeletal muscle in type 2 diabetic rats," Journal of Chinese Integrative Medicine, vol. 9, no. 10, pp. 1133-1137, 2011.

[28] J. M. A. Hannan, L. Ali, B. Rokeya et al., "Soluble dietary fibre fraction of Trigonella foenum-graecum (fenugreek) seed improves glucose homeostasis in animal models of type 1 and type 2 diabetes by delaying carbohydrate digestion and absorption, and enhancing insulin action," British Journal of Nutrition, vol. 97, no. 3, pp. 514-521, 2007.

[29] G. Jelodar, M. Maleki, and S. Sirus, "Effect of walnut leaf, coriander and pomegranate on blood glucose and histopathology of pancreas of alloxan induced diabetic rats," African Journal of Traditional, Complementary and Alternative Medicines, vol. 4, no. 3, pp. 299-305, 2007.

[30] M. Vessal, F. Zal, and M. Vasei, "Effects of Teucrium polium on oral glucose tolerance test, regeneration of pancreatic islets and activity of hepatic glucokinase in diabetic rats," Archives of Iranian Medicine, vol. 6, no. 1, pp. 35-39, 2003.

[31] K. M. Fararh, Y. Atoji, Y. Shimizu, T. Shiina, H. Nikami, and T. Takewaki, "Mechanisms of the hypoglycaemic and immunopotentiating effects of Nigella sativa L. oil in streptozotocininduced diabetic hamsters," Research in Veterinary Science, vol. 77, no. 2, pp. 123-129, 2004.

[32] C. F. Lima, M. F. Azevedo, R. Araujo, M. Fernandes-Ferreira, and C. Pereira-Wilson, "Metformin-like effect of Salvia officinalis (common sage): is it useful in diabetes prevention?" British Journal of Nutrition, vol. 96, no. 2, pp. 326-333, 2006.

[33] B. Farzami, D. Ahmadvand, S. Vardasbi, F. J. Majin, and S. Khaghani, "Induction of insulin secretion by a component of Urtica dioica leave extract in perifused Islets of Langerhans and its in vivo effects in normal and streptozotocin diabetic rats," Journal of Ethnopharmacology, vol. 89, no. 1, pp. 47-53, 2003.

[34] R. Nmila, R. Gross, H. Rchid et al., "Insulinotropic effect of Citrullus colocynthis fruit extracts," Planta Medica, vol. 66, no. 5, pp. 418-423, 2000.

[35] S. Pournourmohammadi, F. Sharififar, E. Talebiyan, M. Khayatian, R. Sh, and A. H. Moslehi, "Effect of olive Leaf (Olea europaea L.) on glucose-stimulated insulin secretion from isolated pancreatic islets of rat," Journal of Medicinal Plants, vol. 7, no. 28, pp. 38-149, 2008.

[36] J. Patel, "Diabetes: managing dyslipidaemia," Clinical Evidence, vol. 2008, article 0610, 2008.

[37] A. S. M. Moosa, M. U. Rashid, A. Z. S. Asadi, N. Ara, M. Uddin, and A. Ferdaus, "Hypolipidemic effects of fenugreek 
seed powder," Bangladesh Journal of Pharmacologyl, vol. 1, pp. 64-67, 2006.

[38] A. Eidi and M. Eidi, "Antidiabetic effects of sage (Salvia officinalis L.) leaves in normal and streptozotocin-induced diabetic rats," Diabetes and Metabolic Syndrome, vol. 3, no. 1, pp. 40-44, 2009.

[39] F. Karimi, S. Abbasi, and A. R. Bateni, "The effect of Teucrium polium on blood glucose in diabetes mellitus type 2; a comparison with glibenclamide," Iranian South Medical Journal, vol. 2, pp. 96-103, 2002.

[40] A. Ghorbani, M. R. Hadjzadeh, Z. Rajaei, and S. B. Zendehbad, "Effects of fenugreek seeds 6 on adipogenesis and lipolysis in normal and diabetic rat," Pakistan Journal of Biological Sciences, vol. 17, no. 4, pp. 523-528, 2014.

[41] R. K. Schindhelm, M. Diamant, J. M. Dekker, M. E. Tushuizen, T. Teerlink, and R. J. Heine, "Alanine aminotransferase as a marker of non-alcoholic fatty liver disease in relation to type 2 diabetes mellitus and cardiovascular disease," Diabetes/Metabolism Research and Reviews, vol. 22, no. 6, pp. 437443, 2006.

[42] B. Vozarova, N. Stefan, R. S. Lindsay et al., "High alanine aminotransferase is associated with decreased hepatic insulin sensitivity and predicts the development of type 2 diabetes," Diabetes, vol. 51, no. 6, pp. 1889-1895, 2002.

[43] H. Madani, P. Rahimi, and P. Mahzoni, "Effects of hydroalcoholic extract of Juglans regia leaves on activity of AST and ALT enzymes in alloxan- induced diabetic rats," Pharmaceutical Sciences, vol. 15, no. 2, pp. 213-218, 2009.

[44] S. Shtukmaster, P. Ljubuncic, and A. Bomzon, "The effect of an aqueous extract of Teucrium polium on glutathione homeostasis in vitro: a possible mechanism of its hepatoprotectant action," Advances in Pharmacological Sciences, vol. 2010, Article ID 938324, 7 pages, 2010.

[45] A. Eidi, M. Eidi, and M. Sokhteh, "Effect of fenugreek (Trigonella foenum-graecum L) seeds on serum parameters in normal and streptozotocin-induced diabetic rats," Nutrition Research, vol. 27, no. 11, pp. 728-733, 2007.

[46] K. H. Abu Sitta, M. S. Shomah, and A. S. Salhab, "Hepatotoxicity of Teucrium polium L tea: supporting evidence in mice models," Australian Journal of Medical Herbalism, vol. 21, no. 4, pp. 106110, 2009.

[47] J. K. Aronson, Meyler's Side Effects of Herbal Medicines, Elsevier, Oxford, UK, 2009. 

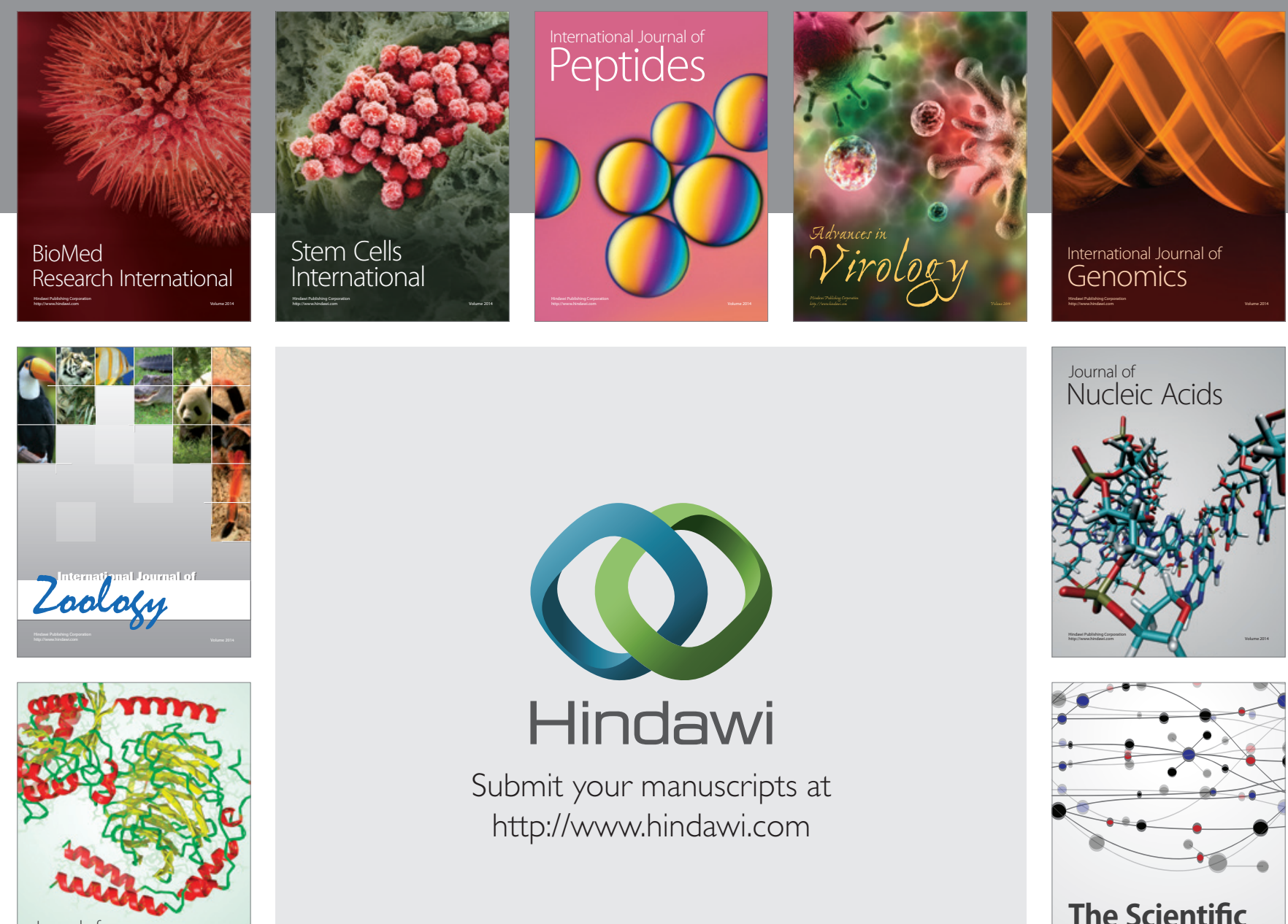

Submit your manuscripts at

http://www.hindawi.com

Journal of
Signal Transduction
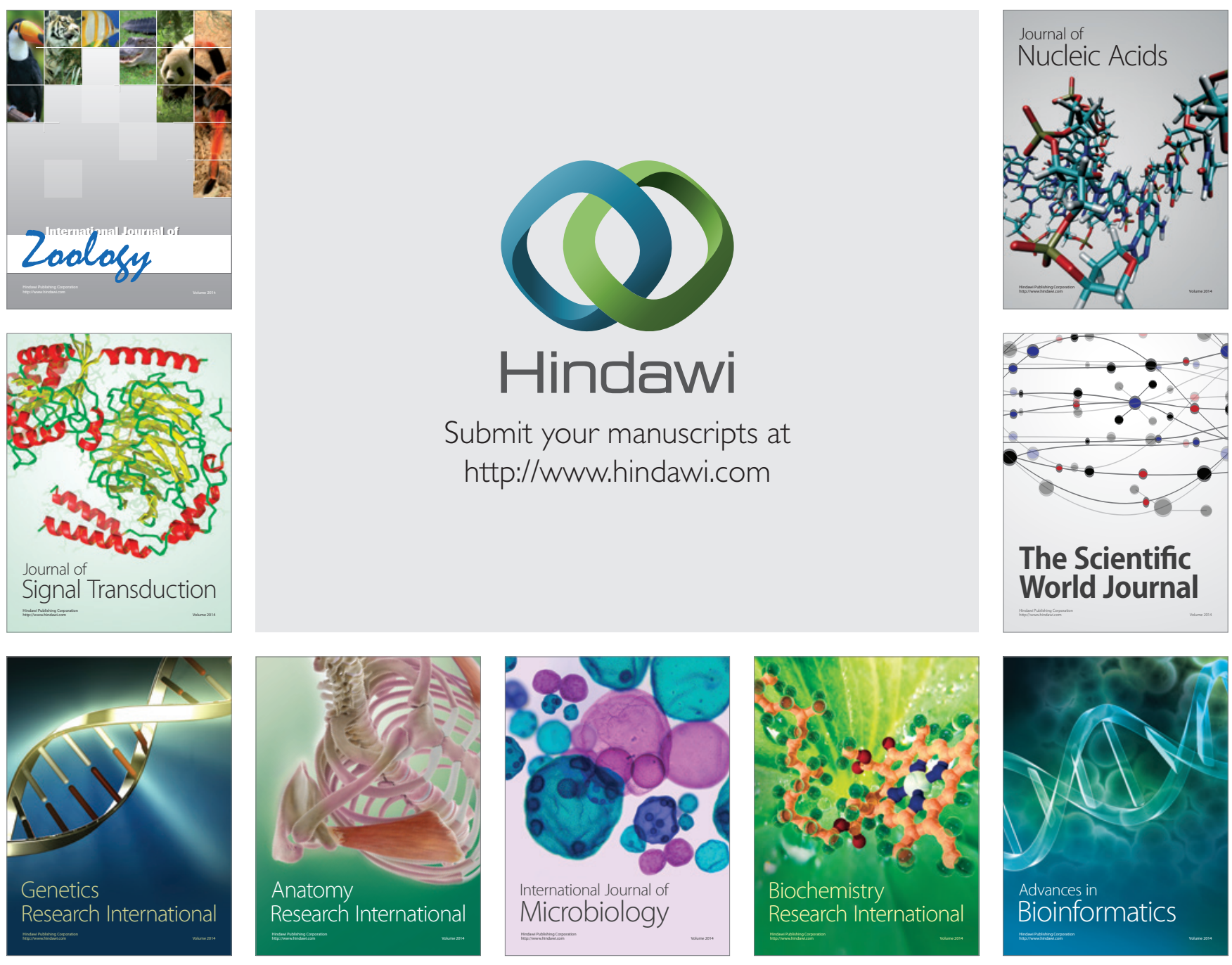

The Scientific World Journal
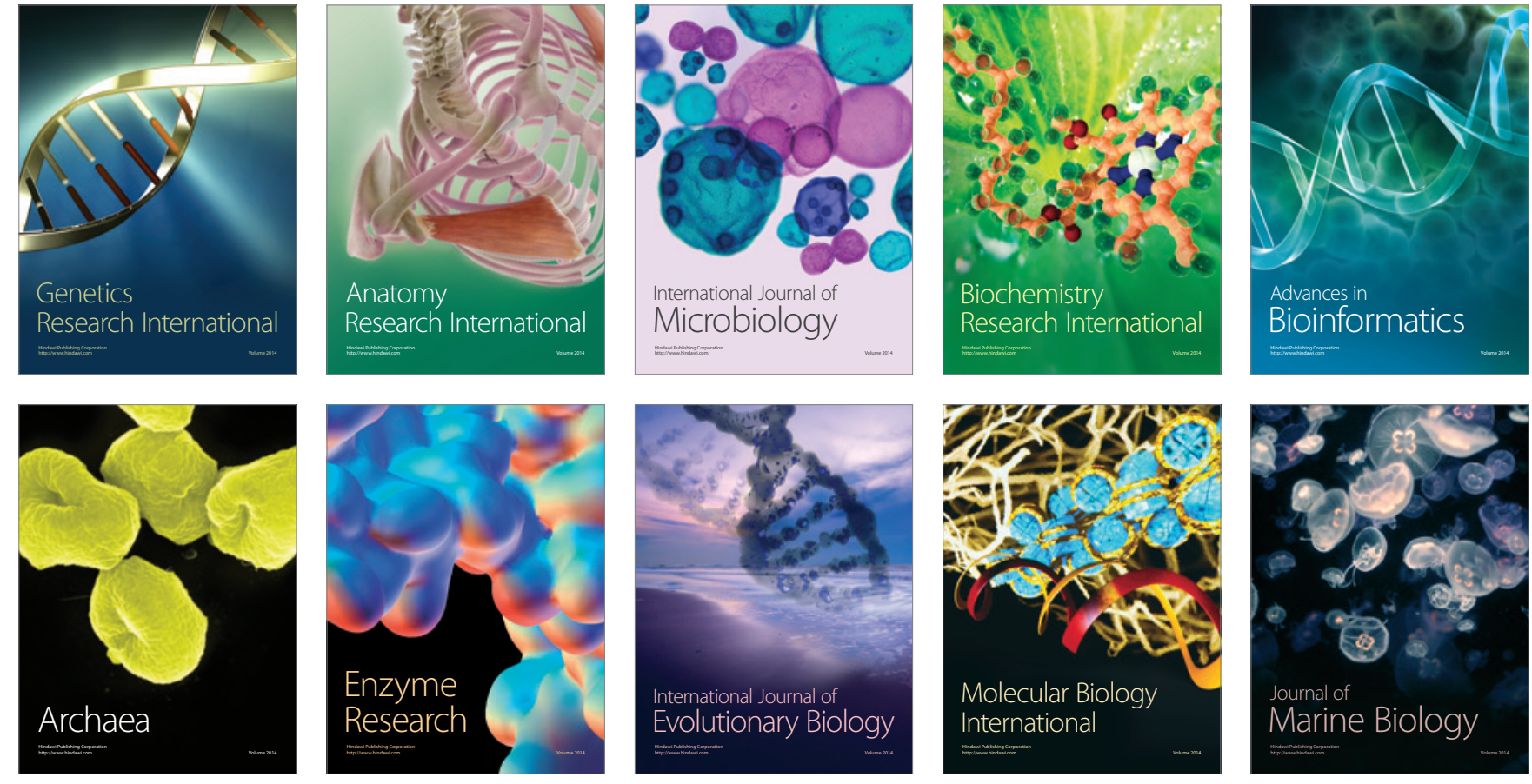